\title{
THE
}

\section{Influence of single nucleotide polymorphisms in factor VIII and von Willebrand factor genes on plasma factor VIII activity: the ARIC Study}

\author{
Marco Campos \\ L. Buchanan \\ University of Rhode Island, buchanan@uri.edu \\ Fuli Yu \\ Maja Barbalic \\ Yang Xiao
}

See next page for additional authors

Follow this and additional works at: https://digitalcommons.uri.edu/php_facpubs

Terms of Use

All rights reserved under copyright.

\section{Citation/Publisher Attribution}

Campos, M., Buchanan, A., Yu, F., Barbalic, M., Xiao, Y., Chambles, L. E., Wu, K. K.,...Dong, J.-F. (2012)

Influence of single nucleotide polymorphisms in factor VIII and von Willebrand factor genes on plasma factor VIII activity: the ARIC Study. Blood, 119(8), 1929-1934. doi: 10.1182/blood-2011-10-383661 Available at: http://dx.doi.org/10.1182/blood-2011-10-383661

This Article is brought to you for free and open access by the Pharmacy Practice at DigitalCommons@URI. It has been accepted for inclusion in Pharmacy Practice Faculty Publications by an authorized administrator of DigitalCommons@URI. For more information, please contact digitalcommons-group@uri.edu. 


\section{Authors}

Marco Campos, L. Buchanan, Fuli Yu, Maja Barbalic, Yang Xiao, Lloyd E. Chambless, Kenneth W. Wu, Aaron R. Folsom, Eric Boerwinkle, and Jing-fei Dong 


\title{
Influence of single nucleotide polymorphisms in factor VIII and von Willebrand factor genes on plasma factor VIII activity: the ARIC Study
}

\author{
${ }^{*}$ Marco Campos, ${ }^{1}{ }^{*}$ Ashley Buchanan, ${ }^{2}$ *Fuli Yu, ${ }^{3}$ Maja Barbalic, ${ }^{4}$ Yang Xiao, ${ }^{5}$ Lloyd E. Chambless, ${ }^{2}$ Kenneth K. Wu, ${ }^{6}$ \\ Aaron R. Folsom, ${ }^{7}$ Eric Boerwinkle, ${ }^{4}$ and Jing-fei Dong ${ }^{1,5}$ \\ ${ }^{1}$ Cardiovascular Sciences Section, Department of Medicine, Baylor College of Medicine, Houston, TX; 2Department of Biostatistics, University of North Carolina, \\ Chapel Hill, NC; ${ }^{3 H u m a n}$ Genome Sequencing Center, Department of Human and Molecular Genetics, Baylor College of Medicine, Houston, TX; ${ }^{4 H u m a n}$ \\ Genetic Center, The University of Texas School of Public Health, Houston, TX; ${ }^{5}$ Puget Sound Blood Center, Seattle, WA; 6 National Health Research Institutes, \\ Taipei, Taiwan; and 7Division of Epidemiology and Community Health, School of Public Health, University of Minnesota, Minneapolis, MN
}

\begin{abstract}
Factor VIII (FVIII) functions as a cofactor for factor IXa in the contact coagulation pathway and circulates in a protective complex with von Willebrand factor (VWF). Plasma FVIII activity is strongly influenced by environmental and genetic factors through VWF-dependent and -independent mechanisms. Single nucleotide polymorphisms (SNPs) of the coding and promoter sequence in the FVIII gene have been extensively studied for effects on FVIII synthesis, secretion, and activity, but impacts of non-
\end{abstract}

disease-causing intronic SNPs remain largely unknown. We analyzed FVIII SNPs and FVIII activity in 10434 healthy Americans of European (EA) or African (AA) descent in the Atherosclerosis Risk in Communities (ARIC) study. Among covariates, age, race, diabetes, and $\mathrm{ABO}$ contributed $2.2 \%$, $3.5 \%, 4 \%$, and $10.7 \%$ to $\mathrm{FVIII}$ intersubject variation, respectively. Four intronic FVIII SNPs associated with FVIII activity and 8 with FVIII-VWF ratio in a sex- and race-dependent manner. The FVIII haplotypes AT and
GCTTTT also associated with FVIII activity. Seven VWF SNPs were associated with FVIII activity in EA subjects, but no FVIII SNPs were associated with VWF Ag. These data demonstrate that intronic SNPs could directly or indirectly influence intersubject variation of FVIII activity. Further investigation may reveal novel mechanisms of regulating FVIII expression and activity. (Blood. 2012;119(8):1929-1934)

\section{Introduction}

Factor VIII (FVIII) functions as a cofactor for factor IXa in the contact coagulation pathway and is synthesized as a single-chain precursor with a domain structure of n-A1-A2-B-A3-C1-C2-c. ${ }^{1,2}$ It is secreted as a noncovalent heterodimer produced from intracellular cleavage at 2 peptide bonds in the B domain: $\operatorname{Arg}^{1313}-\mathrm{Ala}^{1314}$ and $\mathrm{Arg}^{1648}-\mathrm{Glu}^{1649}$, generating a heavy (A1, A2, and a part of B domains) and a light chain (A3, C1, and C2 domains). ${ }^{2,3}$ FVIII is synthesized in multiple cell types, but hepatic sinusoidal endothelial cells appear to be a major source of circulating FVIII. ${ }^{4,5}$ FVIII is highly sensitive to proteolysis and is protected by forming a high-affinity complex $\left(K_{\mathrm{d}}=0.2-0.5 \mathrm{nM}\right)$ with VWF in the circulation. 6 , The half-life of VWF-bound FVIII is significantly longer than plasma FVIII from patients lacking VWF (type III VWD). ${ }^{8,9}$ This FVIII-VWF complex is formed primarily through an interaction between the light chain of $\mathrm{FVIII}^{7,10}$ and the $\mathrm{D}^{\prime}$ and D3 domains of VWF. ${ }^{11-13}$ FVIII is activated to FVIIIa when it is cleaved by thrombin at A1-A2 and A2-B junctions in the heavy chain and in the $\mathrm{N}$-terminal region of the light chain, ${ }^{3}$ whereas cleavage in the light chain releases FVIIII from VWF. ${ }^{14}$

The molar ratio of circulating FVIII and VWF is $\sim 1: 50$ of FVIII to VWF monomer. ${ }^{6}$ However, the 2 molecules can form a complex in a 1:1 stoichiometry in vitro, suggesting that all FVIII-binding sites on a VWF multimer are available and the FVIII-VWF ratio may primarily depend on the amount of circulating FVIII. ${ }^{6,7}$ The baseline level of FVIII varies considerably among individuals and increase further in conditions such as inflammation. ${ }^{15}$ This variation is caused by multiple factors, but genetic influence is significant. One major genetic factor is ABO blood types, ${ }^{16,17}$ which affects FVIII activity primarily because of ABO impact on VWF. ${ }^{18}$ However, a small, but significant, VWF-independent ABO effect on FVIII is also reported in healthy subjects. ${ }^{19}$

The FVIII gene spans $186 \mathrm{~kb}$ on chromosome X (q28) and contains 26 exons that range from $69 \mathrm{bp}$ to $3.1 \mathrm{~kb}$ in size. ${ }^{20,21} \mathrm{FVIII}$ introns vary from $0.2 \mathrm{~kb}$ for intron 17 to $32 \mathrm{~kb}$ for intron 22 . Within intron 22 , there are 2 distinct non- $F$ VIII gene elements controlled by a bidirectional promoter. $^{22,23}$ The FVIII mRNA is $\sim 9 \mathrm{~kb}$ that encodes a mature glycoprotein of 2332 aa without known alternatively spliced forms. ${ }^{2}$ The FVIII locus is polymorphic with a majority of single nucleotide polymorphisms (SNPs) located in introns, ${ }^{24,25}$ but impacts of these intronic and non-disease-causing SNPs on plasma FVIII activity remain largely unknown. In this study, we correlated 19 FVIII SNPs with FVIII activity measured in plasma samples from 10434 healthy American subjects of European (EA, 8056) or African descent (AA, 2378) in the Atherosclerosis Risk in Communities (ARIC) Study. In addition, 75 VWF SNPs that we have previously studied for their impact on VWF $\mathrm{Ag}^{26}$ were also analyzed for their effect on FVIII activity.

\section{Methods}

\section{Study population}

ARIC is a prospective cohort study designed to assess atherosclerosis, clinical atherosclerotic diseases, and cardiovascular risk factors. Baseline
Submitted October 2, 2011; accepted December 18, 2011. Prepublished online as Blood First Edition paper, January 4, 2012; DOI 10.1182/blood2011-10-383661.

*M.C., A.B., and F.Y. contributed equally.

The online version of this article contains a data supplement.
The publication costs of this article were defrayed in part by page charge payment. Therefore, and solely to indicate this fact, this article is hereby marked "advertisement" in accordance with 18 USC section 1734. 
A

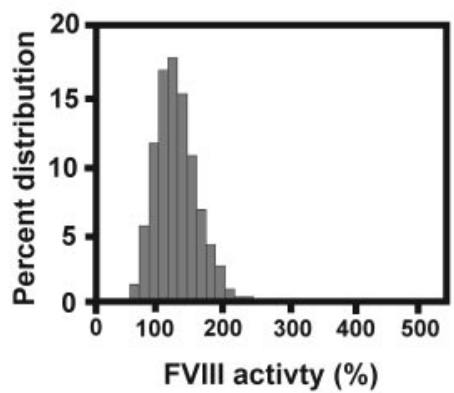

B

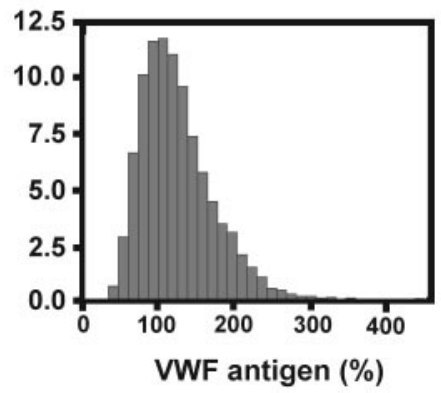

C

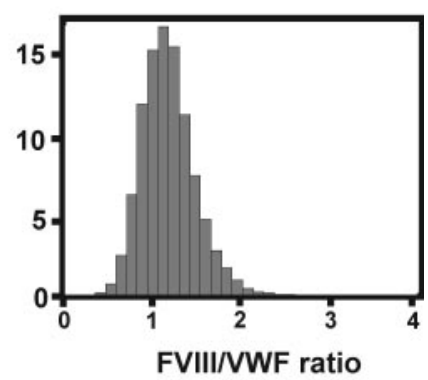

Figure 1. Distributions of FVIII activity, VWF Ag, and FVIII-VWF ratio in 10434 subjects included in the study.

samples and demographic data were collected from 15792 subjects of 45 to 64 years of age using probability sampling from Forsyth County, NC; Jackson, MS; the northwestern suburbs of Minneapolis, MN; and Washington County, MD from 1987 to 1989 (http://www.cscc.unc.edu/aric/). This study included Americans of EA and AA descent. Subjects who did not consent to share genetic information were excluded from the study $(\mathrm{N}=45)$. The use of these data were approved by the institutional review boards of all participating institutions for the ARIC study.

\section{Baseline measurements}

Blood was drawn from an antecubital vein from subjects who were asked to arrive at clinic after fasting at least 12 hours. FVIII activity was measured by the ability of a testing sample to correct clotting time of human FVIII-deficient plasma and reported as a percentage (George King Biomedical Inc). ${ }^{27}$ VWF Ag was determined by a commercial ELISA kit (American Bioproducts) and reported as a percentage of the Universal Coagulation Reference Plasma (Thromboscreen, Pacific Hemostasis; Curtin Matheson Scientific Inc). The reliability coefficient (1 - intraindividual variance/total variance) obtained from repeat testing of individuals over several weeks was 0.68 for VWF and 0.86 for FVIII. Age, race, sex, body mass index (BMI), hypertension, diabetes, ever smoking status, and ABO genotype were adjusted for their known impacts on VWF and FVIII. ${ }^{27,28}$

\section{SNP genotyping and haplotype construction}

SNPs genotyped on an Affymetrix 6.0 platform in the region encompassing the FVIII gene (153 717264 to 153904192 on X chromosome) and VWF gene (5 $928997-6098180$ on chromosome 12) were included in the data analyses. A total of 19 FVIII and 75 VWF SNPs were analyzed for the study (supplemental Table 1, available on the Blood Web site; see the Supplemental Materials link at the top of the online article), where letters A and B indicate major and minor alleles. We also used the fastPHASE 1.2 program to resolve haplotypes from the unphased SNP genotype data and Haploview to determine regions in strong linkage disequilibrium (LD), their cosegregation rates, and underlying haplotypes in each region. ${ }^{26,29}$

Because of known associations between O blood type and plasma VWF levels and FVIII activity, blood type $\mathrm{O}$ was genotyped based on a single base deletion (G) at nt 261 (RS8176719) that shifts the reading frame to generate a premature termination codon. The truncated enzyme is unable to transfer a sugar moiety to the $\mathrm{H} \mathrm{Ag}$. This SNP was therefore used to distinguish between type $\mathrm{O}$ (homozygous for nt261) and type non-O subjects in the analysis (nt261 was on one allele or absent). ${ }^{30}$

\section{Data analysis}

All SNPs were evaluated for Hardy-Weinberg Equilibrium (HWE) by $\chi^{2}$ test statistics or exact tests, as appropriate. HWE was tested for each race-by-sex level separately. The majority of FVIII SNPs were in HWE for EA women except RS5987068 and RS5987061, which did not have enough variation to test HWEs, and RS12392769, which was not in HWE for AA women. Because the FVIII gene is on the X chromosome, tests of HWE were irrelevant for men. Statistical significance was determined at the level of $P<.0005$ using a Bonferroni adjustment for multiple comparisons, which was calculated based on a formula of 0.05 divided by a total of 94 SNPs included in analysis.

Linear models were used to evaluate the association of FVIII activity with each FVIII SNP. The analysis was stratified on race and sex. The models were adjusted for age, hypertension, diabetes, BMI, ever smoking, and ABO. For haplotype analyses at each block of interest, a numerical variable was assigned for each common haplotype by counting the frequency $(0,1$, or 2$)$ of the haplotype for women, but there are only 2 possible levels of the haplotype variable ( 0 or 1$)$ for men because the FVIII gene is on the $\mathrm{X}$ chromosome. Linear models were also used to assess the association between FVIII or VWF plasma levels and haplotype frequencies.

\section{Results}

Among the 15792 ARIC participants of EA and AA descent, 10434 were included in the analyses after exclusion of subjects for lacking data on (1) FVIII activity, VWF Ag, or both ( $\mathrm{n}=280)$; (2) SNPs on both genes $(n=3032)$; or (3) ABO genotypes $(n=1898)$. Demographics for the 10434 subjects are displayed in supplemental Table 2. There were significant differences in age, BMI, and smoking status between the 4 race-by-sex groups. EA subjects were older and have a lower BMI, compared with AA subjects, for both sexes. More men were in ever-smoking status than women were for both races. AA subjects had higher prevalences of diabetes and hypertension compared with EA subjects.

\section{FVIII activity and association with VWF Ag levels}

The mean plasma FVIII activity and VWF Ag levels were $127.5 \%$ $(\mathrm{SD}=37.3$ and median at $123 \%)$ and $113.5 \%(\mathrm{SD}=45.2$ and median at $106 \%$ ), respectively. Both mean values were $>100 \%$ for reasons to be further determined. One possibility is the inclusion of a large number of AA subjects who are known to have higher FVIII and VWF. Both measurements varied considerably among the cohort subjects (20\%-540\% for FVIII and 22\%-412\% for VWF, Figure 1). The FVIII-VWF ratio ranged from 0.18 to 3.73 with a mean ratio of 1.20. The correlation coefficient between FVIII activity and VWF Ag were 0.70 (women) and 0.69 (men) for EA subjects and 0.69 (women) and 0.74 (men) for AA subjects, respectively. FVIII activity and VWF Ag were significantly different among the 4 race-by-sex groups. FVIII activity was higher for women, compared with men (for both race), and for AA subjects, compared with EA subjects. AA subjects also had a higher VWF Ag, compared with EA subjects. The FVIII/VWF ratio was higher in women, compared with men, but was comparable between the race groups (Table 1). When both measurements were grouped in 
From www.bloodjournal.org by guest on January 19, 2018. For personal use only.

Table 1. Mean (SD) of FVIII activity and VWF Ag by race and sex $(\mathrm{N}=10434)$

\begin{tabular}{lcccccc}
\hline Characteristic & Total & EA women, $\mathbf{N}=\mathbf{4 2 8 2}$ & EA men, $\mathbf{N}=\mathbf{3 7 7 4}$ & AA women, $\mathbf{N}=\mathbf{1 5 0 5}$ & AA men, $\mathbf{N}=\mathbf{8 7 3}$ & $\boldsymbol{P}^{\star}$ \\
\hline Factor VIII (\%) & $127.59(37.32)$ & $125.51(34.05)$ & $121.13(33.19)$ & $144.49(46.31)$ & $135.44(41.84)$ & $<1 \times 10^{-31}$ \\
VWF (\%) & $113.53(45.15)$ & $108.44(41.10)$ & $111.34(42.36)$ & $128.15(54.42)$ & $122.74(51.16)$ & $<1 \times 10^{-31}$ \\
FVIII-VWF ratio† & $1.20(0.31)$ & $1.23(0.32)$ & $1.16(0.30)$ & $1.22(0.35)$ & $1.18(0.30)$ & $4.27 \times 10^{-25}$ \\
\hline
\end{tabular}

EA indicates Americans of European descent; and AA, Americans of African descent.

*ANOVA.

†One subject was excluded from the statistics for the ratio because he was considered to be an outlier with a ratio of $6.13(>15 \times$ SD).

quartiles, FVIII activity was found in parallel with VWF Ag in $39 \%$ to $66 \%$ of subjects, whereas up to $27 \%$ mismatched. Among these mismatched, $2 \%$ of subjects had a significant split where a very high VWF Ag (fourth quartile) was paired with a very low FVIII activity (first quartile) or vice versa (Table 2). This split between the 2 measurements varied from $1 \%$ to $3 \%$ in the 4 race-by-sex groups (supplemental Table 3).

There were 5005 subjects (48\%) who are the O blood type and 5429 subjects $(52 \%)$ who are non-O blood type. ABO genotype accounted for $10.7 \%$ of FVIII variation when it was analyzed together with nongenetic covariates in a linear model (supplemental Table 4). Among the nongenetic covariates used for adjustment, race, diabetes, and age accounted for $4.0 \%, 3.5 \%$, and $2.2 \%$ of the variance, respectively.

\section{SNP and haplotype correlation with FVIII activity}

There were 19 FVIII SNPs available in the ARIC genome-wide association study (GWAS) database. Eighteen of them were intronic (94.7\%) and 1 was nonsynonymous from exon 26 (RS1800297) that changes a methionine residue at the position of 2257 to a valine residue (M2257V). Seventy-five VWF SNPs were also analyzed for their effect on FVIII activity. Among them, 70 were intronic $(93.3 \%)$ and 5 exonic $(6.7 \%)$, but all coding SNPs were synonymous. ${ }^{26}$ Among the 19 FVIII SNPs, RS6643714 was

Table 2. Quartile of VWF Ag by quartile of FVIII activity ( $N=10434)$

\begin{tabular}{lccccc}
\hline & \multicolumn{5}{c}{ VWF } \\
\cline { 2 - 6 } Quartile & 1st (\%) & 2nd (\%) & 3rd (\%) & 4th (\%) & Total (\%) \\
\hline FVIII, 1st & $1753(66)$ & $642(24)$ & $194(8)$ & $56(2)$ & $2645(25)$ \\
FVIII, 2nd & $678(26)$ & $1071(41)$ & $692(27)$ & $214(8)$ & $2655(25)$ \\
FVIII, 3rd & $183(7)$ & $705(27)$ & $1001(39)$ & $704(27)$ & $2593(25)$ \\
FVIII, 4th & $42(2)$ & $217(8)$ & $692(27)$ & $1590(62)$ & $2541(24)$ \\
\hline
\end{tabular}

significantly associated with FVIII activity after adjustment for age, sex, smoking status, diabetes, and hypertension. A further adjustment with ABO yielded 3 additional SNPs that were significantly associated with FVIII activity (Table 3). The association of these 4 SNPs with FVIII activity was found in EA men, but not in EA women and AA subjects of either sex. All 4 SNPs were also associated with the FVIII-VWF ratio, but again in EA men only (Table 4). In addition, 4 new SNPs were associated with the FVIII-VWF ratio in EA subjects of either sex, but not in AA subjects.

The large ARIC database allowed us to construct FVIII haplotypes that included rare alleles to identify specific SNPs that are transmitted together and to determine whether their effects are additive. Using the fastPHASE 1.2 program, we identified 2 major haplotype blocks that are in linkage disequilibrium in the FVIII gene and accounted for $82.4 \%, 73.5 \%, 83.6 \%$, and $74.3 \%$ of all haplotypes for EA women, AA women, EA men, and AA men, respectively (Figure 2). SNPs in each LD haplotype were identical for male and female subjects, but varied significantly between AA and EA subjects (Table 5), indicating a highly diverse coaggregation of SNPs between EA and AA subjects. Among the haplotypes, AT in block 1 and GCTTTT in block 2 were associated with FVIII activity in EA men after adjustment for age, BMI, ever smoking, diabetes, hypertension, and ABO (Table 6).

\section{Cross-genetic influence between FVIII and VWF SNPs}

Finally, we examined cross-influence between the 2 measurements and found no FVIII SNPs associated with VWF Ag levels before or after adjustment for $\mathrm{ABO}$ and other covariates. In contrast, 5 and 2 VWF SNPs were associated with FVIII activity for EA women and EA men, respectively (Table 7), but not for AA subjects.

Table 3. Adjusted mean of FVIII activity $(\%)$ by FVIII genotype for EA males $(\mathrm{N}=3774)$

\begin{tabular}{|c|c|c|c|c|c|}
\hline \multirow[b]{2}{*}{ SNP $^{\star}$} & \multirow[b]{2}{*}{ Location } & \multirow[b]{2}{*}{ ABO adjusted $\dagger$} & \multicolumn{2}{|c|}{ FVIII activity (\%) } & \multirow[b]{2}{*}{$P$} \\
\hline & & & AA & BB & \\
\hline \multirow[t]{2}{*}{ RS5945122 } & \multirow[t]{2}{*}{ Intron13 } & No & $121.69(0.57)$ & $117.35(1.34)$ & $2.9 \times 10^{-3}$ \\
\hline & & Yes & $121.77(0.54)$ & $116.88(1.27)$ & $3.9 \times 10^{-4}$ \\
\hline \multirow[t]{2}{*}{ RS6643714‡ } & \multirow[t]{2}{*}{ Intron14 } & No & $122.51(0.66)$ & $118.50(0.86)$ & $2.2 \times 10^{-4}$ \\
\hline & & Yes & $122.52(0.63)$ & $118.49(0.81)$ & $8.8 \times 10^{-5}$ \\
\hline \multirow[t]{2}{*}{ RS7061362‡ } & \multirow[t]{2}{*}{ Intron11 } & No & $121.70(0.57)$ & $117.29(1.34)$ & $2.5 \times 10^{-3}$ \\
\hline & & Yes & $121.78(0.54)$ & $116.82(1.27)$ & $3.2 \times 10^{-4}$ \\
\hline \multirow[t]{2}{*}{ RS5945258 } & \multirow[t]{2}{*}{ Intron11 } & No & $121.70(0.57)$ & $117.24(1.34)$ & $2.2 \times 10^{-3}$ \\
\hline & & Yes & $121.78(0.54)$ & $116.80(1.26)$ & $3 \times 10^{-4}$ \\
\hline
\end{tabular}

All models adjusted for age, BMI, diabetes, hypertension, and smoking status.

EA indicates Americans of European descent.

${ }^{*}$ RS5986899, RS5987057, RS5987068, RS5987073, RS7056252, RS12014480, RS1800297, RS5987056, RS5987061, RS7357998, and RS12392769 were too sparse to be analyzed for EA men.

†Participants with "-G" at RS8176719 and "GT" at RS8176746 were excluded from the ABO genotype definition (N=1284) and those with no information on RS8176719 or RS8176746 were also excluded $(\mathrm{N}=614)$.

‡Due to small counts, AB genotype was combined with minor (BB) genotype. 
Table 4. Statistical significance of association of FVIII SNPs with the FVIII-VWF ratio for EA subjects

\begin{tabular}{|c|c|c|c|}
\hline SNP & $\begin{array}{c}\mathrm{ABO} \\
\text { adjusted }\end{array}$ & $\begin{array}{c}P \\
(\text { men, } N=3774)^{\star}\end{array}$ & $\begin{array}{c}P \\
\text { (women, } N=4282) \dagger\end{array}$ \\
\hline \multirow[t]{2}{*}{ RS4898352 } & No & $5.2 \times 10^{-6}$ & $3.1 \times 10^{-6}$ \\
\hline & Yes & $2.8 \times 10^{-6}$ & $4.6 \times 10^{-6}$ \\
\hline \multirow[t]{2}{*}{ RS5987077 } & No & $1.2 \times 10^{-5}$ & $5.6 \times 10^{-6}$ \\
\hline & Yes & $6.1 \times 10^{-6}$ & $7.2 \times 10^{-6}$ \\
\hline \multirow[t]{2}{*}{ RS1470586 } & No & $1.2 \times 10^{-6}$ & $8.2 \times 10^{-6}$ \\
\hline & Yes & $8.5 \times 10^{-7}$ & $1.3 \times 10^{-5}$ \\
\hline \multirow[t]{2}{*}{ RS6643622 } & No & $4.7 \times 10^{-5}$ & $1.1 \times 10^{-5}$ \\
\hline & Yes & $2.3 \times 10^{-5}$ & $1.7 \times 10^{-5}$ \\
\hline \multirow[t]{2}{*}{ RS5945122 } & No & $2.1 \times 10^{-4}$ & $4.9 \times 10^{-4}$ \\
\hline & Yes & $3.8 \times 10^{-4}$ & $5 \times 10^{-4}$ \\
\hline \multirow[t]{2}{*}{ RS5945258ł } & No & $1.7 \times 10^{-4}$ & $5.6 \times 10^{-4}$ \\
\hline & Yes & $2.9 \times 10^{-4}$ & $5.7 \times 10^{-4}$ \\
\hline \multirow[t]{2}{*}{ RS6643714‡ } & No & $2.2 \times 10^{-7}$ & $8.9 \times 10^{-4}$ \\
\hline & Yes & $1.5 \times 10^{-7}$ & $1 \times 10^{-4}$ \\
\hline \multirow[t]{2}{*}{ RS7061362 } & No & $2 \times 10^{-4}$ & $5.1 \times 10^{-4}$ \\
\hline & Yes & $3.7 \times 10^{-4}$ & $5.1 \times 10^{-4}$ \\
\hline
\end{tabular}

Models are adjusted for age, BMI, ever smoking, diabetes, and hypertension (1 subject with outlier was not included from these models).

SNP indicates single nucleotide polymorphism; and EA, Americans of European descent.

*There were 37 men were missing information on at least 1 of the predictors and were excluded from these models.

†There were 27 women were missing information on at least 1 of the predictors and were excluded from these models.

¥These SNPs were associated with FVIII activity in EA males as individual and in haplotypes.

\section{Discussion}

Using the ARIC database, we analyzed 19 FVIII SNPs and haplotypes for their association with FVIII activity and FVIIIVWF ratio. We also examined a cross-genetic influence of VWF SNPs that we have recently studied ${ }^{26}$ on FVIII activity. Consistent with a previous report, ${ }^{27} \mathrm{FVIII}$ activity varied significantly among subjects (Figure 1) and was higher in AA subjects than EA subjects, but the FVIII-VWF ratio was comparable between the 2 ethnic groups (Table 1). This difference may be in part attributed to a higher BMI and increased prevalence of diabetes and hypertension in AA subjects (supplemental Figure 2A) because these covariates are known to associate with inflammation, a condition that increases secretion of acute-phase reactants such as FVIII and VWF. Women had significantly higher FVIII activity and a greater FVIII-VWF ratio compared with men. Age, race, and diabetes had the strongest influence on variations of FVIII activity, whereas the influence of BMI and sex was smaller, but significant (supplemental Figure 4). ABO (defined as O type vs non-O type) accounted for $10.7 \%$ of FVIII variation when it was analyzed together with environmental covariates in a single linear model. This study has also made 3 novel findings.

First, it has been reported that FVIII varies with VWF to keep its ratio relatively constant over a wide range of VWF levels. ${ }^{24}$ When analyzed in quartiles, we did find that $39 \%-66 \%$ of subjects had FVIII activities in parallel with VWF levels (Figure 2). However, this parallel distribution between the 2 measurements was not detected in up to $61 \%$ of subjects. Among them, 2\% subjects had either a very high VWF level paired with a very low FVIII or a very high FVIII paired with a very low VWF. This extreme split was consistently observed (1\%-3\%) when data were analyzed by race and sex (supplemental Figure 3), suggesting that FVIII and VWF ratio varies among individuals considerably more than previously

\section{A FVIII hapmap for EA subjects}

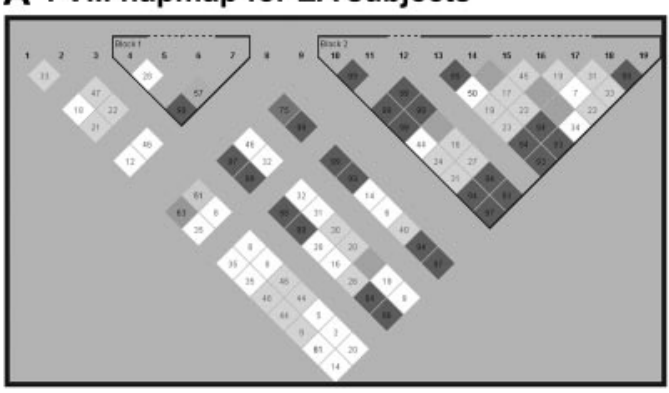

\section{B FVIII hapmap for AA subjects}

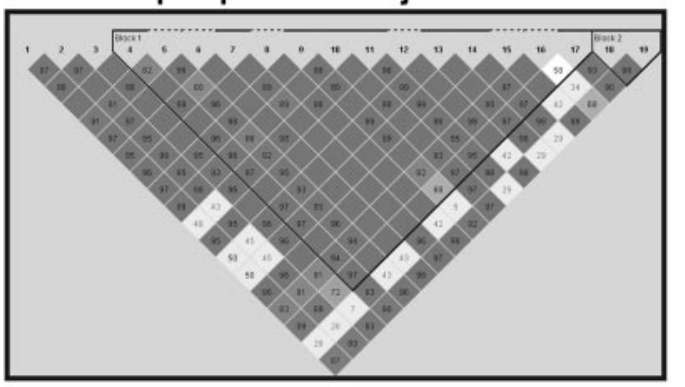

\section{AA haplotype blocks}

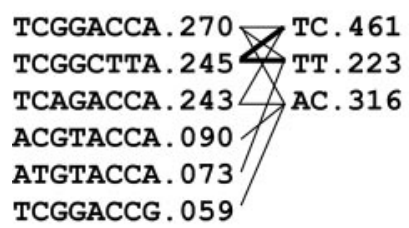

D EA haplotype blocks

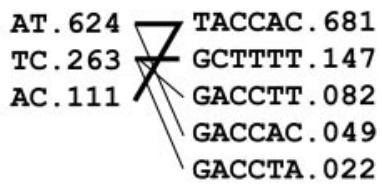

Figure 2. Haplotypes constructed from 19 available FVIII SNPs in a cohort of 10434 subjects.

reported. This extreme split may be explained by variable rates of synthesis of the 2 factors, different association kinetics between FVIII, and assay variations. Whether VWF multimer size and conformation affect its association with FVIII is not known. This split may be physiologically significant because the FVIII-VWF ratio is used to distinguish accelerated VWF clearance found in a subset of patients with VWD. ${ }^{31}$

Second, we identified 4 FVIII SNPs that were significantly associated with FVIII activity after adjustment for age, sex, BMI, smoking status, diabetes, hypertension, and ABO genotypes (Table 3 ). These positive SNPs are intronic and clustered in intron 11, 13, and 14 that flank exons encoding A2 and B domains of the FVIII

Table 5. Haplotype blocks for FVIII SNPs

\begin{tabular}{|c|c|c|c|}
\hline \multicolumn{2}{|c|}{ AA subject } & \multicolumn{2}{|c|}{ EA subject } \\
\hline Block 1 & Block 2 & Block 1 & Block 2 \\
\hline rs4898352 & rs5987077 & rs4898352 & rs6643622 \\
\hline rs6643714* & rs1470586 & rs6643714* & rs5945122* \\
\hline rs12014480 & & & rs5945258* \\
\hline rs6643622 & & & rs7061362* \\
\hline rs5945122* & & & rs5987077 \\
\hline rs5945258* & & & rs1470586 \\
\hline \multicolumn{4}{|l|}{ rs7061362* } \\
\hline rs7056252 & & & \\
\hline
\end{tabular}

SNP indicates single nucleotide polymorphism; AA, Americans of African descent; and EA, Americans of European descent.

${ }^{*}$ SNPs that are individually associated with FVIII activity in EA subjects asindicated in Table 3. 
Table 6. Difference (and $\boldsymbol{P}$ value) in adjusted mean FVIII activity (\%) by copy numbers of the haplotype and by $A B O$ adjustment for EA men $(N=3671)$

\begin{tabular}{lllr}
\hline Haplotype & ABO adjusted & $\boldsymbol{P}$ & Difference \\
\hline Block 1 $^{*}$ & & & \\
AT & No & $6 \times 10^{-4}$ & 3.74 \\
& Yes & $2 \times 10^{-4}$ & 3.89 \\
TC & No & $7.7 \times 10^{-3}$ & -3.20 \\
& Yes & $7.3 \times 10^{-3}$ & -3.05 \\
\hline AC & No & $8 \times 10^{-2}$ & -2.95 \\
& Yes & $2.9 \times 10^{-2}$ & -3.50 \\
Block 2 & & & \\
\hline TACCAC & No & $9.5 \times 10^{-3}$ & 2.96 \\
& Yes & $1.2 \times 10^{-2}$ & 2.71 \\
GCTTTT & No & $1.5 \times 10^{-3}$ & -4.71 \\
& Yes & $2 \times 10^{-4} \dagger$ & -5.24 \\
\hline GACCTT & No & $7.9 \times 10^{-1}$ & -0.50 \\
& Yes & $9.5 \times 10^{-1}$ & 0.12 \\
\hline GACCAC & No & $9.2 \times 10^{-1}$ & 0.25 \\
& Yes & $6.5 \times 10^{-1}$ & 1.11 \\
\hline GACCTC & No & $9.8 \times 10^{-1}$ & 0.07 \\
& Yes & $8.2 \times 10^{-1}$ & 0.79 \\
\hline
\end{tabular}

EA indicates Americans of European descent.

*Adjusted for age, BMI, diabetes, hypertension, and ever smoking.

heavy chain. ${ }^{24}$ The effect sizes of these intronic SNPs are smaller, but often additive. Interestingly, these SNPs were found to associate with FVIII activity only in EA men, even though they were also detected in EA women and AA subjects. These 4 positive SNPs were also associated with the FVIII-VWF ratio in EA men and 4 additional SNPs were associated with the ratio in EA men and women. In addition, 2 major haplotype boxes were identified from these 19 SNPs and counted for $73.5 \%-83.6 \%$ of all FVIII gene haplotypes (Figure 2). SNPs included in the 2 haplotype boxes were significantly different between EA and AA subjects (Table 5). The haplotype TC in box 1 and haplotype GCTTTT in box 2 were associated with FVIII activity after adjustment for environmental covariates and $\mathrm{ABO}$, but only in EA men (Figure 6). Together, these data suggest that intronic SNPs in the FVIII gene could affect FVIII activity, potentially by affecting gene splicing and/or mRNA stability, especially those at or near a splice site, or serving as a marker for remote variations. For the former, Bagnall et al reported an intronic mutation that creates a new donor splice site in intron 1 and is believed to be responsible for developing hemophilia A. ${ }^{32}$ For the latter, several SNPs outside of the FVIII gene are found to associate with FVIII activity in a recent GWAS by the Cohorts for Heart and Aging Research in Genomic Epidemiology (CHARGE) Consortium. ${ }^{33}$ Our analyses reveal a striking sex and race disparity in SNP association that has not been previously reported and its cause remains unknown. The finding that more SNPs were associated with the FVIII-VWF ratio than with FVIII activity would suggest that VWF levels may contribute to this disparity. The FVIII gene location to the $\mathrm{X}$ chromosome may also contribute to a sex-dependent association. As shown in Table 1, men had $\sim 5 \%$ less plasma FVIII activity than women, even though they have only one $\mathrm{X}$ chromosome, suggesting the presence of genetic or environmental modifiers to regulate rates of FVIII synthesis, secretion, and/or clearance in a sex-specific manner. Alternatively, this disparity may be attributable to an insufficient sample size to detect subtle differences associated with intronic SNPs for AA subjects. However, this is less likely because frequencies of minor genotypes in AA subjects were actually significantly higher than EA subjects (supplemental Table 1A).

Third, we have identified 5 and 2 VWF SNPs that associated with FVIII activity in EA women and men, respectively, after adjustment for covariates and ABO (Table 6). The association was only found in EA subjects, but differentially distributed between EA men and EA women. Furthermore, all these associative VWF SNPs, except RS723190, were previously associated with VWF Ag levels in the ARIC cohort. ${ }^{26}$ RS1063857, which results in a synonymous amino acid substitution at position 795 of VWF, was associated with VWF Ag and FVIII activity in a recent GWAS study. ${ }^{33}$ Whether the association is sex or race specific was not determined in these studies. In contrast, no FVIII SNPs were associated with VWF levels, suggesting that VWF determines this cross-genetic influence primarily because of its function as a FVIII carrier.

Table 7. Adjusted mean of FVIII activity (\%) by VWF SNPs

\begin{tabular}{|c|c|c|c|c|c|}
\hline \multirow[b]{2}{*}{ VWF SNP } & \multirow[b]{2}{*}{ ABO adjusted } & \multicolumn{3}{|c|}{ FVIII activity for VWF genotype, mean (SEM) } & \multirow[b]{2}{*}{$P$} \\
\hline & & AA & AB & BB & \\
\hline \multicolumn{6}{|c|}{ EA women, $N=4282^{*} \dagger \S$} \\
\hline \multirow[t]{2}{*}{ RS216315 } & No & $126.50(0.54)$ & $120.66(1.22)$ & $117.91(5.02)$ & $2.4 \times 10^{-5}$ \\
\hline & Yes & $126.53(0.51)$ & $120.53(1.14)$ & $117.88(4.69)$ & $2.7 \times 10^{-6}$ \\
\hline \multirow[t]{2}{*}{ RS216318 } & No & $126.51(0.54)$ & $120.66(1.22)$ & $117.87(4.90)$ & $2.2 \times 10^{-5}$ \\
\hline & Yes & $126.54(0.51)$ & $120.51(1.14)$ & $117.89(4.58)$ & $2.3 \times 10^{-6}$ \\
\hline \multirow[t]{2}{*}{ RS216299 } & No & $126.30(0.55)$ & $121.67(1.20)$ & $121.81(4.46)$ & $1.5 \times 10^{-3}$ \\
\hline & Yes & $126.42(0.51)$ & $121.19(1.12)$ & $120.51(4.17)$ & $6.2 \times 10^{-5}$ \\
\hline \multirow[t]{2}{*}{ RS216295 } & No & $126.34(0.55)$ & $121.70(1.21)$ & $119.86(4.92)$ & $1.1 \times 10^{-3}$ \\
\hline & Yes & $126.42(0.51)$ & $121.36(1.13)$ & $118.76(4.59)$ & $8 \times 10^{-5}$ \\
\hline \multirow[t]{2}{*}{ RS216298 } & No & $126.32(0.54)$ & $121.61(1.21)$ & $119.77(4.80)$ & $8.7 \times 10^{-4}$ \\
\hline & Yes & $126.43(0.51)$ & $121.15(1.13)$ & $118.81(4.48)$ & $3.6 \times 10^{-5}$ \\
\hline \multicolumn{6}{|c|}{ EA men, $N=3774^{\star} \dagger$} \\
\hline \multirow[t]{2}{*}{ RS1063857 } & No & $118.24(0.83)$ & $122.25(0.77)$ & $125.11(1.45)$ & $1.9 \times 10^{-5}$ \\
\hline & Yes & $118.50(0.78)$ & $122.11(0.73)$ & $124.81(1.38)$ & $4.3 \times 10^{-5}$ \\
\hline \multirow[t]{2}{*}{ RS723190‡§ } & No & $120.42(0.56)$ & & $125.67(1.57)$ & $1.6 \times 10^{-3}$ \\
\hline & Yes & $120.36(0.53)$ & & $126.13(1.48)$ & $2.5 \times 10^{-4}$ \\
\hline
\end{tabular}

SNP indicates single nucleotide polymorphism; and EA, Americans of European descent.

${ }^{*}$ All means were adjusted for age, sex, BMI, diabetes, hypertension, and ever-smoking status.

†RS7968035, RS2239143, RS16932374, and RS3213721 were too sparse to analyze for both EA women and men.

fDue to small counts, AB genotype was combined with the minor BB genotype.

§All SNPs except RS723190 were previously associated with VWF Ag. ${ }^{31}$ 
In summary, we have found considerable variation in FVIII activity and FVIII-VWF ratios among the ARIC subjects. Four and 8 FVIII SNPs from a pool of 19 were associated with FVIII activity and FVIII-VWF ratio, respectively. We also identified 2 major haplotype blocks associated with FVIII activity. Strikingly, these associations were primarily found EA men, with some in EA female, but none in AA subjects. The impact of sex and race on FVIII activity remains to be further investigated. The results suggest that these intronic SNPs could directly regulate FVIII expression or act as markers for its regulation.

\section{Acknowledgments}

The authors thank the staff and participants of the ARIC Study for their important contributions.

This work is supported by an Atherosclerosis Risk in Communities (ARIC) contract and by National Heart, Lung, and Blood Institute (NHLBI) grant HL71895. The ARIC Study is carried out as a collaborative study supported by NHLBI contracts N01-HC55015, N01-HC-55016, N01-HC-55018, N01-HC-55019, N01-HC55020, N01-HC-55021, and N01-HC-55022.

\section{Authorship}

Contribution: M.C. contributed to study design and to the writing of the manuscript; A.B. analyzed data and contributed to the writing of the manuscript; F.Y. constructed and analyzed the haplotype and contributed to the writing of the manuscript; M.B. screened for FVIII and VWF SNPs in the ARIC GWAS database; Y.X. analyzed data; L.C. developed the hypothesis and analyzed data; K.W. performed basic measurements and contributed to the writing of the manuscript; A.F. contributed to study design, collected data, and contributed to the writing of the manuscript; E.B. contributed to study design, genotyped SNP, and contributed to the writing of the manuscript; and J.-f.D. developed the hypothesis, contributed to study design, analyzed data, and wrote the manuscript.

Conflict-of-interest disclosure: The authors declare no competing financial interests.

Correspondence: Jing-fei Dong, Puget Sound Blood Center, 921 Terry Ave, Seattle, WA 98104; e-mail: jfdong@psbcresearch.org.

\section{References}

1. Wood WI, Capon DJ, Simonsen CC, et al. Expression of active human factor VIII from recombinant DNA clones. Nature. 1984;312(5992):330337.

2. Vehar GA, Keyt B, Eaton D, et al. Structure of human factor VIII. Nature. 1984;312(5992):337-342.

3. Fay PJ, Haidaris PJ, Smudzin TM. Human factor VIIla subunit structure. Reconstruction of factor VIIla from the isolated A1/A3-C1-C2 dimer and A2 subunit. J Biol Chem. 1991;266(14):89578962.

4. Stel HV, van der Kwast TH, Veerman EC. Detection of factor VIII/coagulant antigen in human liver tissue. Nature. 1983;303(5917):530-532.

5. van der Kwast TH, Stel HV, Cristen E, Bertina RM, Veerman EC. Localization of factor VIIIprocoagulant antigen: an immunohistological survey of the human body using monoclonal antibodies. Blood. 1986;67(1):222-227.

6. Vlot AJ, Koppelman SJ, van den Berg MH, Bouma BN, Sixma JJ. The affinity and stoichiometry of binding of human factor VIII to von Willebrand factor. Blood. 1995;85(11):3150-3157.

7. Lollar P, Hill-Eubanks DC, Parker CG. Association of the factor VIII light chain with von Willebrand factor. J Biol Chem. 1988;263(21):1045110455.

8. Menache D, Aronson DL, Darr F, et al. Pharmacokinetics of von Willebrand factor and factor VIIIC in patients with severe von Willebrand disease (type 3 VWD): estimation of the rate of factor VIIIC synthesis. Cooperative Study Groups. Br J Haematol. 1996;94(4):740-745.

9. Tuddenham EG, Lane RS, Rotblat F, et al. Response to infusions of polyelectrolyte fractionated human factor VIII concentrate in human haemophilia A and von Willebrand's disease. $\mathrm{Br} \mathrm{J}$ Haematol. 1982;52(2):259-267.

10. Hamer RJ, Koedam JA, Beeser-Visser NH, Bertina RM, van Mourik JA, Sixma JJ. Factor VIII binds to von Willebrand factor via its $\mathrm{Mr}-80,000$ light chain. Eur J Biochem. 1987;166(1):37-43.

11. Foster PA, Fulcher CA, Marti T, Titani K, Zimmerman TS. A major factor VIII binding domain resides within the amino-terminal 272 amino acid residues of von Willebrand factor. $J$ Biol Chem. 1987;262(18):8443-8446.

12. Takahashi $Y$, Kalafatis M, Girma JP, Sewerin K, Andersson LO, Meyer D. Localization of a factor VIII binding domain on a 34 kilodalton fragment of the N-terminal portion of von Willebrand factor. Blood. 1987;70(5):1679-1682.

13. Bahou WF, Ginsburg D, Sikkink R, Litwiller R, Fass DN. A monoclonal antibody to von Willebrand factor (vWF) inhibits factor VIII binding. Localization of its antigenic determinant to a nonadecapeptide at the amino terminus of the mature vWF polypeptide. J Clin Invest. 1989; 84(1):56-61.

14. Hill-Eubanks DC, Parker CG, Lollar P. Differential proteolytic activation of factor VIII-von Willebrand factor complex by thrombin. Proc Natl Acad Sci U S A. 1989;86(17):6508-6512.

15. Chandler WL, Rodgers GM, Sprouse JT, Thompson AR. Elevated hemostatic factor levels as potential risk factors for thrombosis. Arch Pathol Lab Med. 2002;126(11):1405-1414.

16. Jenkins PV, O'Donnell JS. ABO blood group determines plasma von Willebrand factor levels: a biologic function after all? Transfusion. 2006; 46(10):1836-1844.

17. Orstavik KH, Magnus $\mathrm{P}$, Reisner $\mathrm{H}$, Berg K Graham JB, Nance W. Factor VIII and factor IX in a twin population. Evidence for a major effect of ABO locus on factor VIII level. Am J Hum Genet. 1985;37(1):89-101.

18. Vlot AJ, Mauser-Bunschoten EP, Zarkova AG, et al. The half-life of infused factor VIII is shorter in hemophiliac patients with blood group $\mathrm{O}$ than in those with blood group A. Thromb Haemost. 2000;83(1):65-69.

19. Morange PE, Tregouet DA, Frere C, et al. Biological and genetic factors influencing plasma factor VIII levels in a healthy family population: results from the Stanislas cohort. Br J Haematol. 2005; 128(1):91-99.

20. Gitschier J, Wood WI, Goralka TM, et al. Characterization of the human factor VIII gene. Nature. 1984;312(5992):326-330.

21. Poustka A, Dietrich A, Langenstein G, Toniolo D, Warren ST, Lehrach H. Physical map of human $X q 27-q$ ter: localizing the region of the fragile $X$ mutation. Proc Natl Acad Sci U S A. 1991;88(19): 8302-8306.

22. Levinson B, Kenwrick S, Lakich D, Hammonds G $\mathrm{Jr}$, Gitschier J. A transcribed gene in an intron of the human factor VIII gene. Genomics. 1990;7(1): $1-11$.

23. Levinson B, Kenwrick S, Gamel P, Fisher K, Gitschier J. Evidence for a third transcript from the human factor VIII gene. Genomics. 1992; 14(3):585-589.

24. Thompson AR. Structure and function of the factor VIII gene and protein. Semin Thromb Hemost. 2003;29(1):11-22.

25. Mancuso DJ, Tuley EA, Westfield LA, et al. Structure of the gene for human von Willebrand factor. J Biol Chem. 1989;264(33):19514-19527.

26. Campos M, Sun W, Yu F, et al. Genetic determinants of plasma von Willebrand factor antigen levels: a target gene SNP and haplotype analysis of ARIC cohort. Blood. 2011;117(19):5224-5230.

27. Folsom AR, Wu KK, Shahar E, Davis CE. Association of hemostatic variables with prevalent cardiovascular disease and asymptomatic carotid artery atherosclerosis. The Atherosclerosis Risk in Communities (ARIC) Study Investigators. Arterioscler Thromb. 1993;13(12):1829-1836.

28. Conlan MG, Folsom AR, Finch A et al. Associations of factor VIII and von Willebrand factor with age, race, sex, and risk factors for atherosclerosis. The Atherosclerosis Risk in Communities (ARIC) Study. Thromb Haemost. 1993;70(3):380385.

29. Scheet P, Stephens M. A fast and flexible statistical model for large-scale population genotype data: applications to inferring missing genotypes and haplotypic phase. Am J Hum Genet. 2006; 78(4):629-644.

30. Yip SP. Sequence variation at the human $A B O$ locus. Ann Hum Genet. 2002;66(pt 1):1-27.

31. Eikenboom JC, Castaman G, Kamphuisen PW, Rosendaal FR, Bertina RM. The factor VIII/von Willebrand factor ratio discriminates between reduced synthesis and increased clearance of von Willebrand factor. Thromb Haemost. 2002;87(2): 252-257.

32. Bagnall RD, Waseem NH, Green PM, Colvin B, Lee C, Giannelli F. Creation of a novel donor splice site in intron 1 of the factor VIII gene leads to activation of a $191 \mathrm{bp}$ cryptic exon in two haemophilia A patients. Br J Haematol. 1999;107(4): 766-771.

33. Smith NL, Chen MH, Dehghan A, et al. Novel associations of multiple genetic loci with plasma levels of factor VII, factor VIII, and von Willebrand factor: The CHARGE (Cohorts for Heart and Aging Research in Genome Epidemiology) Consortium. Circulation. 2010;121(12):1382-1392. 


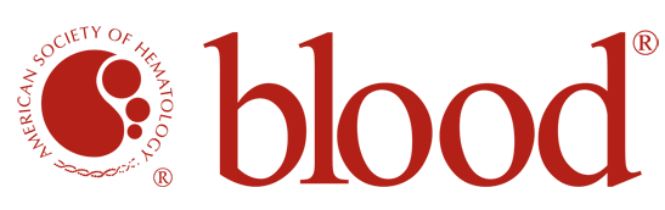

2012 119: 1929-1934

doi:10.1182/blood-2011-10-383661 originally published online January 4, 2012

\section{Influence of single nucleotide polymorphisms in factor VIII and von Willebrand factor genes on plasma factor VIII activity: the ARIC Study}

Marco Campos, Ashley Buchanan, Fuli Yu, Maja Barbalic, Yang Xiao, Lloyd E. Chambless, Kenneth $\mathrm{K}$. Wu, Aaron R. Folsom, Eric Boerwinkle and Jing-fei Dong

Updated information and services can be found at:

http://www.bloodjournal.org/content/119/8/1929.full.html

Articles on similar topics can be found in the following Blood collections

Thrombosis and Hemostasis (1128 articles)

Information about reproducing this article in parts or in its entirety may be found online at:

http://www.bloodjournal.org/site/misc/rights.xhtml\#repub_requests

Information about ordering reprints may be found online at:

http://www.bloodjournal.org/site/misc/rights.xhtml\#reprints

Information about subscriptions and ASH membership may be found online at:

http://www.bloodjournal.org/site/subscriptions/index.xhtml

Blood (print ISSN 0006-4971, online ISSN 1528-0020), is published weekly by the American Society of Hematology, 2021 L St, NW, Suite 900, Washington DC 20036.

Copyright 2011 by The American Society of Hematology; all rights reserved. 